\title{
Water diffusion and hydrolysis effect on the structure and dynamics of epoxy-anhydride networks
}

\author{
Guillermina Capiel $^{\text {a, }}{ }^{*}$, Luis A. Miccio ${ }^{\text {b, c, }{ }^{* *} \text {, Pablo E. Montemartini a }}$, \\ Gustavo A. Schwartz ${ }^{\text {b, c }}$ \\ ${ }^{\text {a }}$ Composite Materials (CoMP), Institute of Materials Science and Technology (INTEMA), University of Mar del Plata (UNMdP), National Research Council \\ (CONICET), Solis 7575, Mar del Plata, Buenos Aires, Argentina \\ ${ }^{\mathrm{b}}$ Centro de Física de Materiales CSIC-UPV/EHU - Materials Physics Center (MPC), Paseo Manuel de Lardizábal 5, 20018 San Sebastián, Spain \\ ${ }^{c}$ Donostia International Physics Center (DIPC), Paseo Manuel de Lardizabal 4, 20018 San Sebastián, Spain
}

\section{A R T I C L E I N F O}

\section{Article history:}

Received 18 August 2016

Received in revised form

12 June 2017

Accepted 13 June 2017

Available online 15 June 2017

\section{Keywords:}

Water uptake

Dielectric spectroscopy

AFM

\begin{abstract}
A B S T R A C T
Epoxy-anhydride networks have been analyzed in terms of water uptake and degradation behavior by means of broadband dielectric spectroscopy and atomic force microscopy. It has been found that water absorption produces a chemical reaction in the polymer networks, in turn causing a plasticizing effect and changing their mechanical properties. We demonstrate that a non invasive dielectric spectroscopy analysis of the segmental dynamics can be performed in order to quantitatively describe the degradation effects, as well as their influence in the mechanical properties at the nanoscale.
\end{abstract}

() 2017 Elsevier Ltd. All rights reserved.

\section{Introduction}

Thermosetting polymers based in epoxy resins are widely used in technological applications due to their outstanding thermal and mechanical properties. In particular, in aeronautical and aerospace industries, as well as in pipeline systems, epoxy based polymers are used as the matrices of the composite materials. Resistance to hostile environmental conditions that induce changes in both their designed properties and their durability is therefore a must. Moreover, service life performance prediction is a key factor in technology adoption decisions, and risk analysis based methods need models to achieve accurate in service behavior predictions. As a result, there is a well-documented literature dealing with several aspects of polymer hydrolysis i.e.: the effect of structure on hydrophilicity [1,2], sensitivity to chain scission, kinetic modeling of direct, reversible and diffusion controlled hydrolysis [3,4] and

\footnotetext{
* Corresponding author. Composite Materials (CoMP), Institute of Materials Science and Technology (INTEMA), University of Mar del Plata (UNMdP), National Research Council (CONICET), Solis 7575, Mar del Plata, Buenos Aires, Argentina.

** Corresponding author. Centro de Física de Materiales CSIC-UPV/EHU, Paseo Manuel de Lardizabal 5, 20018 San Sebastián, Spain.

E-mail addresses: guillermina.capiel@fi.mdp.edu.ar (G. Capiel), luisalejandro_ miccio@ehu.es (L.A. Miccio).
}

modeling of elastically active chains consumption [5].

It has been shown that epoxy based thermosets are affected by humid aging. The sorption processes in epoxy based materials produce not only physical but also chemical modifications, which are not always accurately represented by the classical Fickian [6] model. Water-polymer interactions produce plasticization, swelling and microstructural changes [7] due to chemical degradation. Polymers with ester groups in their structures like epoxy cross-linked by anhydrides (AEs) can suffer hydrolytic chemical degradation, followed by the leaching of low molecular weight species resulting from the reaction between cleavable ester groups and water [8-10]. In addition, these small species could eventually be responsible for osmotic cracking [11,12]. In summary, the hydrolysis of ester groups in thermosetting polymers is an extremely complex process that, depending on the polymer hydrophilicity, could be controlled by water diffusion or behave as an autocatalytic process in which non-random chain scission occurs [10,15].

In order to connect plasticization and chemical degradation effects on non ideal networks' mechanical behavior, network architecture modifications during water uptake and changes in macromolecular mobility need to be analyzed. Recent reports take advantage of the combination of nuclear magnetic resonance (NMR) and dynamic mechanical analysis (DMA) results [16], but this connection is still unclear. Since the polymer dynamics is very 
sensitive to changes in chemical composition, crosslink density and network environment, and considering that broadband dielectric spectroscopy (BDS) can follow polymer dynamics quite accurately over a large frequency and temperature window, it naturally appears as a very interesting approach for studying the above mentioned effects. In particular, the main advantage of BDS is related to its broad frequency $\left(10^{-2}\right.$ to $\left.10^{7} \mathrm{~Hz}\right)$ and temperature range $(100-400 \mathrm{~K})$. This remarkable breadth allows relating the observed dielectric response to slow and/or fast molecular events. BDS has been widely used to characterize the molecular dynamics in systems that undergo a chemical and/or physical change as a result of chemical reaction, crystallization, vitrification, phase separation, etc. [17-22], but only a few of these works deal with sorption processes effects. Here we propose to study the network structural variations at different diffusion stages of an anhydridecured epoxy using BDS and atomic force microscopy (AFM) techniques. Through the study of the dielectric response of an anhydride-cured epoxy that had been immersed in distilled water at three different temperatures $\left(25^{\circ} \mathrm{C}, 80^{\circ} \mathrm{C}\right.$ and $\left.93^{\circ} \mathrm{C}\right)$ for 60 days, we are able to reveal the effects of water absorption on the polymer dynamics. In addition, our AFM measurements yield information about the related structural changes in these materials [18].

\section{Materials and methods}

\subsection{Materials}

Samples were prepared using a commercially available epoxy resin based on diglycidyl ether of bisphenol A (DGEBA, DER 383) supplied by Dow Chemical Co. and a methyltetrahydrophthalic anhydride (MTHPA, Dicure 319, from Novarchem) as curing agent (see Fig. 1a and b). Stoichiometric mixtures with a mass ratio of 100:85 (DGEBA:MTHPA) were used. A 3\% by weight of resin of 2,4,6-tris-(dimethyl-aminomethyl)phenol (from Novarchem) was added as accelerator (Fig. 1c). The system was poured into an aluminium mold in order to obtain $1 \mathrm{~mm}$ thick sheets. Curing schedule included three steps of $1 \mathrm{hr}$ each: a) $60^{\circ} \mathrm{C}$, b) $90^{\circ} \mathrm{C}$ and c) $140{ }^{\circ} \mathrm{C}$. Circular samples with a diameter of $45 \mathrm{~mm}$ were cut from the obtained sheets.

\subsection{Water uptake}

Circular samples were immersed in distilled water at three different temperatures: $25^{\circ} \mathrm{C}, 80^{\circ} \mathrm{C}$ and $93^{\circ} \mathrm{C}$. The samples were placed vertically to ensure fluid contact. At regular intervals the

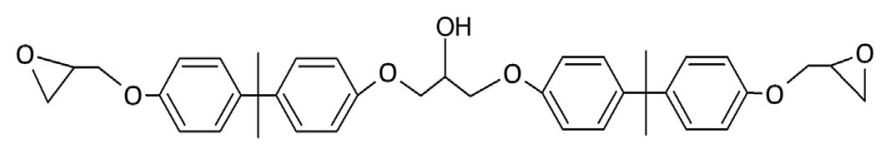

a<smiles>CC1=CCC2C(=O)OC(=O)C2C1</smiles>

b

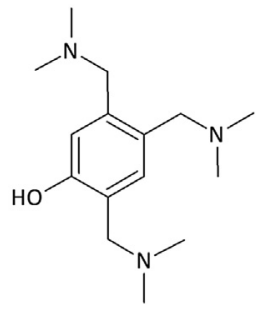

C
Fig. 1. Chemical formula of the reactants: a) Diglycidyl ether of bisphenol A. b) Tetrahydrophthalic anhydride. c) 2, 4, 6-Tri(dimethylaminomethyl)phenol. samples were removed from water, gently dried with a tissue paper to remove the surface moisture, weighed in an analytical balance, and returned into water. The accuracy of the analytical balance used is $10^{-4} \mathrm{~g}$. The mass change during the absorption tests was determined using the following expression

Mass change $(\%)=\frac{m_{t}-m_{i}}{m_{i}} \times 100$

where $m_{t}$ is the sample mass at time $t$, and $m_{i}$ is the initial sample mass.

During the immersion tests, the absorbed water could react with the network ester groups. The hydrolysis rate and in consequence the effects of the chemical degradation on the water absorption behavior is a temperature-dependent process. The immersion temperatures selected in this work included the study of water absorption behavior of the epoxy-anhydride system at a moderate temperature $\left(25^{\circ} \mathrm{C}\right)$ and at a very high temperature $\left(80^{\circ} \mathrm{C}\right.$ and $\left.93^{\circ} \mathrm{C}\right)$. The highest temperature was chosen considering possible industrial applications up to $93^{\circ} \mathrm{C}\left(200^{\circ} \mathrm{F}\right)$.

\subsection{Differential scanning calorimetry (DSC)}

The calorimetric glass transition temperature ( $\mathrm{Tg}$ ) was measured under nitrogen atmosphere by using a DSC Q2000 from TA Instruments. The experiments were conducted at a constant heating/cooling rate of $10{ }^{\circ} \mathrm{C} / \mathrm{min}$. All tests were carried out by following the cycle described hereafter: a) cooling down from $-60{ }^{\circ} \mathrm{C}$ followed by a heating ramp from $-60{ }^{\circ} \mathrm{C}$ to $240{ }^{\circ} \mathrm{C}$; b) cooling from $240{ }^{\circ} \mathrm{C}$ to $20^{\circ} \mathrm{C}$ and c) heating ramp from $20{ }^{\circ} \mathrm{C}$ to $240{ }^{\circ} \mathrm{C}$. Finally, the last cooling/heating cycle (b and c) was repeated.

\subsection{Broadband dielectric spectroscopy (BDS)}

Broadband dielectric spectroscopic measurements were performed on disc shaped samples with a diameter of $40 \mathrm{~mm}$ and a thickness of about $0.7 \mathrm{~mm}$. In order to isolate the effects of degradation processes on the material structure, all samples were previously dried under vacuum (in the low $10^{-2}$ mbar range) for $24 \mathrm{~h}$ at $110{ }^{\circ} \mathrm{C}$ (therefore removing any absorbed water). The samples were placed in between two parallel plate electrodes. For this configuration, the sample capacitance is expressed as $C=\varepsilon^{*}$ $\varepsilon_{0} \mathrm{~A} / \mathrm{d}$ (where $\varepsilon^{*}$ is the complex relative dielectric permittivity of the sample, $\varepsilon_{0}$ is the vacuum permittivity, and $d$ and $A$ are the thickness and the area of the sample, respectively). The material properties are characterized by $\varepsilon^{*}$, which is in turn defined as $\varepsilon^{*}(\omega)=C^{*}(\omega) / C_{0}=\varepsilon^{\prime}(\omega)-i \varepsilon(\omega)$ (where $C_{0}$ is the capacitance of the empty capacitor and $\omega=2 \pi \mathrm{f}$ ). A broadband high-resolution dielectric spectrometer (Novocontrol Alpha) was used to measure the complex dielectric permittivity in the $10^{-2}-10^{6} \mathrm{~Hz}$ frequency range. Isothermal frequency scans were performed every five degrees over the $17-207^{\circ} \mathrm{C}$ range. A Novocontrol Quattro Cryosystem was used for temperature control with a precision better than $0.1^{\circ} \mathrm{C}$.

\subsection{Atomic force microscopy (AFM)}

A nano-mechanical mapping of the surface was performed by means of an atomic force microscope Nanoscope 8 (Bruker), operating in Peak-Force Tapping Mode. RTESP-A 525 probes (Bruker), in turn calibrated with Sapphire (for spring constant and photodiode sensitivity) and a PS calibration sample (for tip radius), were employed. In order to ensure tip integrity, the peak force set point was kept at about $3( \pm 0.5) \mathrm{nN}$ for all the experiments (for a more 
detailed description see Fig. SI 1 in supplementary information).

\section{Results and discussion}

In a first step we have characterized the water absorption process and the corresponding plasticizing and/or chemical reaction effects occurring in the samples. We have therefore defined the aging stage of each sample after a fixed water immersion period in which different degradation stages were achieved (see Table 1). In a second step we have studied the segmental dynamics of these samples in order to relate it with the aging stage. For this purpose, we have employed BDS to study the segmental dynamics of the polymer networks, isolating this response by removing the absorbed water (in this way any water plasticizing effect is neglected). As a last step, we have studied the effect of the above mentioned processes on the local mechanical behavior of the networks by means of peak force tapping AFM.

\subsection{Water uptake and glass transition temperature}

Fig. 2 shows the average normalized mass change of samples aged at 25,80 and $93{ }^{\circ} \mathrm{C}$ as a function of the ratio between the square root of time and sample thickness. Differences from the classical Fickian prediction (which describes water sorption as a diffusion mechanism at a constant rate that eventually reaches an equilibrium absorption value [6]) arise in the whole time frame and temperatures analyzed. Experimental results obtained at low temperature present a positive slope related with a mass increase. At $25^{\circ} \mathrm{C}$ the equilibrium is not reached even after 45 days. Between 100 and $200 \mathrm{~min}^{0.5} / \mathrm{mm}$ (equivalent to 30 days) the samples mass increases from $0.294 \pm 0.019 \%$ to $0.356 \pm 0.025 \%$. At higher temperatures $\left(80{ }^{\circ} \mathrm{C}\right.$ and $\left.93{ }^{\circ} \mathrm{C}\right)$ water absorption presents a faster initial rate (see zone I in Fig. 2), and the previously observed positive slope is more evident (see zone II). Since the chemical reaction between water and ester groups in the anhydride cured epoxy can degrade the epoxy-anhydride networks [8], at longer times it is reasonable to think that the observed slope is originated by this hydrolysis. Several authors [8-11] studied this behavior and have proposed an epoxy anhydride degradation process which includes different steps. In this way, from each hydrolysis event two chain ends are generated in the network, thus leading to a sharp decrease in the cross-linking density. Moreover, as the reaction progresses, the concentration of low molecular weight species increases (reaction products are alcohols and carboxyl acids), remaining in the polymer network until their concentration is higher than their solubility. At that time these species diffuse out of the polymer [12], therefore originating a steep decrease in the observed mass change (e.g. zone III in the curves at $93^{\circ} \mathrm{C}$ ). Although in the time frame analyzed for samples immersed in water at $80^{\circ} \mathrm{C}$, this last step is not observed, it is likely that at longer time chemical degradation could lead to a similar behavior than that observed at $93{ }^{\circ} \mathrm{C}$.

The DSC thermogram of ANH-93-1 shown in Fig. 3 also reveals the water uptake/degradation effects on the polymer network. At low temperatures, the first cooling down cycle shows two exothermic peaks located at $\mathrm{T}_{1}=-39{ }^{\circ} \mathrm{C}$ and $\mathrm{T}_{2}=-44^{\circ} \mathrm{C}$. Since a

Table 1

Degradation conditions for epoxy-anhydride samples studied.

\begin{tabular}{ll}
\hline Sample & Water immersion time and temperature \\
\hline ANH-0 & Neat sample \\
ANH-25 & 30 days at $25{ }^{\circ} \mathrm{C}$ \\
ANH-80 & 30 days at $80^{\circ} \mathrm{C}$ \\
ANH-93 & 30 days at $93{ }^{\circ} \mathrm{C}$ \\
ANH-93-1 & 60 days at $93^{\circ} \mathrm{C}$ \\
\hline
\end{tabular}

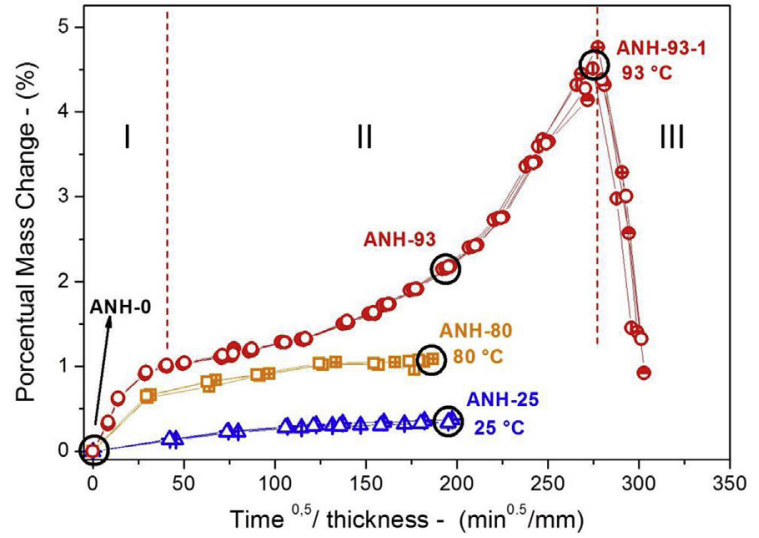

Fig. 2. Mass change (\%) for samples immersed in water at $25^{\circ} \mathrm{C}, 80^{\circ} \mathrm{C}$ and $93^{\circ} \mathrm{C}$. The zones labeled as I, II and III for the $93{ }^{\circ} \mathrm{C}$ curves stand for absorption, absorption + reaction and desorption, respectively. The greatest circles represent the samples at the different degradation conditions (see Table 1).

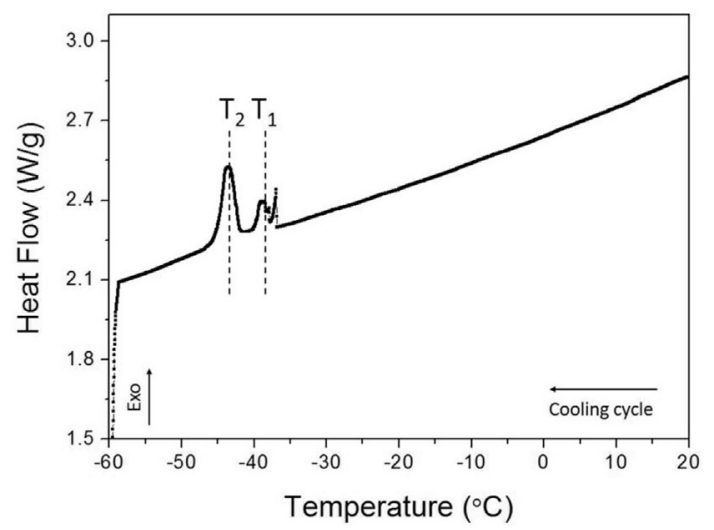

Fig. 3. DSC thermogram for ANH-93-1 (step b, see section 2.3) during cooling down cycle.

depression of the freezing point of water is known to occur for water in confining geometries, these temperatures can be considered to reflect the sizes of pores in the materials. If assuming cylindrical pores it is possible to estimate the pore diameter by the Gibbs-Thomson's equation (Eq. 2) as commonly done for other types of porous systems $[13,14]$.

$D=\frac{-4 v_{m} T_{0} \gamma_{l s}}{H_{f} \Delta T}$

where $D$ is the diameter of the pore, $v_{m}$ the molar volume of ice, $T_{0}$ the melting temperature of bulk water $(273 \mathrm{~K})$ and $\gamma_{l s}$ the surface energy at the ice-water interface. $H_{f}$ is the specific heat of fusion of bulk water and $\Delta T$ the depression of the freezing temperature. By using this equation it is obtained that the freezing temperatures $\mathrm{T}_{1}$ and $\mathrm{T}_{2}$ corresponds to pore sizes of about $1.5-2 \mathrm{~nm}$.

In order to study the effect of the different stages of this absorption-reaction process on the network structure (samples: ANH-0, ANH-93, ANH-93-1, ANH-80 and ANH-25 in Fig. 2), Tg values were also analyzed (see Table 2). In all the cases, $\mathrm{Tg}$ is reported as the inflection point of the heat flow versus temperature curve for the second run (see section 2.3).

As shown in Table 2, the glass transition temperatures for samples immersed at low temperatures (ANH-25) do not differ from the values of neat samples (ANH-0). In this range of 
Table 2

Glass transition temperature $(\mathrm{Tg})$ and broadness $(\Delta \mathrm{Tg})$ determined by DSC $\left( \pm 0.5^{\circ} \mathrm{C}\right)$.

\begin{tabular}{lll}
\hline Sample & $\operatorname{Tg}\left({ }^{\circ} \mathrm{C}\right)$ & Broadness of the glass transition $\Delta \operatorname{Tg}\left({ }^{\circ} \mathrm{C}\right)$ \\
\hline ANH-0 & 134.3 & 5.8 \\
ANH-25 & 133.6 & 6.0 \\
ANH-80 & 131.4 & 6.2 \\
ANH-93 & 122.0 & 9.7 \\
ANH-93-1 & 100.0 & 15.1 \\
\hline
\end{tabular}

temperatures, ester hydrolysis is expected to be negligible. However, ANH-80 already starts showing a slight decrease in $\mathrm{Tg}$ (about $\left.2{ }^{\circ} \mathrm{C}\right)$, while ANH-93 presents a much larger decrease $\left(12.3^{\circ} \mathrm{C}\right)$ and a broader transition (see Table 2 ), thus revealing the increasing material degradation. It is well known that cuts in the polymer network decrease the cross-linking density, in turn increasing the free volume and decreasing the $\mathrm{Tg}$. Moreover, it is also possible that small alcohols and carboxyl acids formed during the hydrolysis plasticize the network before diffusing out of the network. The evidence of the degradation is actually visible in the sample ANH93-1 ( $\mathrm{Tg}$ decrease of $34.3^{\circ} \mathrm{C}$ ), in the form of surface micro-pores and changes in color which can be correlated to the chain scission [15].

\subsection{Changes in the segmental dynamics due to degradation}

As previously described, with the aim to separate the effects of degradation processes on the material structure from any waterpolymer interactions, the water was removed from the samples prior to BDS measurements (Fig. SI 2 shows TGA scans of the drying process). Fig. 4 presents the dielectric loss $\left(\varepsilon^{\prime \prime}\right)$ of dry ANH-0 samples as a function of the excitation frequency $(f)$ for temperatures ranging from $147^{\circ} \mathrm{C}$ to $207^{\circ} \mathrm{C}$. As shown, the temperature range lies slightly above the glass transition temperature of these materials (ANH-0 $\mathrm{Tg}=134{ }^{\circ} \mathrm{C}$, see Table 2 ), so that the corresponding segmental relaxation can be observed within our experimental frequency window. In this way, ANH-0 segmental relaxation appears as a peak that shifts to higher frequencies as the temperature increases. A low frequency contribution of ionic processes (in turn appearing as a sharp increase in the dielectric loss) also steps into the experimental frequency window as the temperature increases. In order to study the segmental relaxation $(\alpha)$ contribution, the spectra were fitted with a Havrilak-Negami [23] (HN) function:

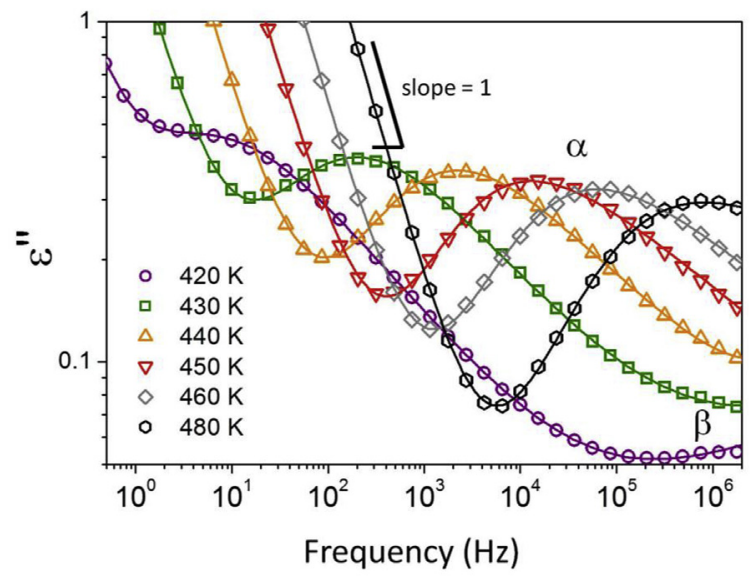

Fig. 4. Dielectric loss as a function of frequency for the initial material (ANH-0) at different temperatures: $147,157,167,177,187$ and $207^{\circ} \mathrm{C}$ (from left to right). Lines stand for the fitting results of the experimental spectra at each temperature.
$\varepsilon^{*}(\omega)-\varepsilon_{\infty}=\frac{\Delta \varepsilon}{\left[1+\left(i \omega \tau_{H N}\right)^{\infty}\right]^{\beta}}$

where $\Delta \varepsilon$ is the relaxation strength, $\tau_{H N}$ is the relaxation time and $\alpha$ and $\beta$ are shape parameters. An additional term was employed to describe the conductivity contribution [17] $\left(-\frac{i \sigma_{0}}{\varepsilon_{0} \omega^{s}}\right)$, where $\varepsilon_{0}$ is the vacuum dielectric permittivity, $s$ is a constant factor $(0<s \leq 1)$ and $\sigma_{0}$ is the dc conductivity when $s=1$.

The same procedure was applied for measuring the samples previously immersed in distilled water for 30 days at $25^{\circ} \mathrm{C}, 80^{\circ} \mathrm{C}$ and $93{ }^{\circ} \mathrm{C}$ (i.e.: ANH-25, ANH-80 and ANH-93, respectively). The observed segmental relaxation processes were analyzed by using the same fitting procedures of ANH- 0 , and the obtained relaxation times, $\tau_{H N}$, are presented in Fig. 5 as a function of the reciprocal of the experimental temperature. As shown, the temperature dependence of the relaxation times follows a clear non linear trend, that in turn is well described by the Vogel-Fulcher-Tammann (VFT) [24] equation:

$\tau(T)=\tau_{0} \exp \left(\frac{B}{T-T_{0}}\right)$

where $B$ and $T_{0}$ are temperature-independent constants. It is noteworthy that from this description, the so called dielectric glass transition temperature can be defined as the temperature corresponding to a relaxation time of $100 \mathrm{~s}$. The obtained results (see Table 3) are in good agreement with the observed calorimetric glass transition temperatures shown in Table 2.

No significant differences were found between the relaxation times of ANH-25 and ANH-0. However, for ANH-80, ANH-93 and ANH-93-1 a clear trend appears: the higher the degradation temperature (or the immersion time at high temperature), the faster the segmental dynamics. Since the samples were previously dried, the observed decrease in the relaxation times can only be related to the changes in the crosslinking density of the networks. Therefore, these results closely agree with the calorimetric trend.

The inset in Fig. 5 presents the observed segmental dielectric strength of ANH-0, ANH-25, ANH-80, ANH-93 and ANH-93-1 plotted as a function of the immersion temperature during water uptake. As shown, there are no significant differences between the observed $\Delta \varepsilon$ in ANH-0, ANH-25 and ANH-80. However, $\Delta \varepsilon$ increases in the case of higher degradation temperatures (ANH-93). Moreover, ANH-93-1 presents even higher intensity than that observed

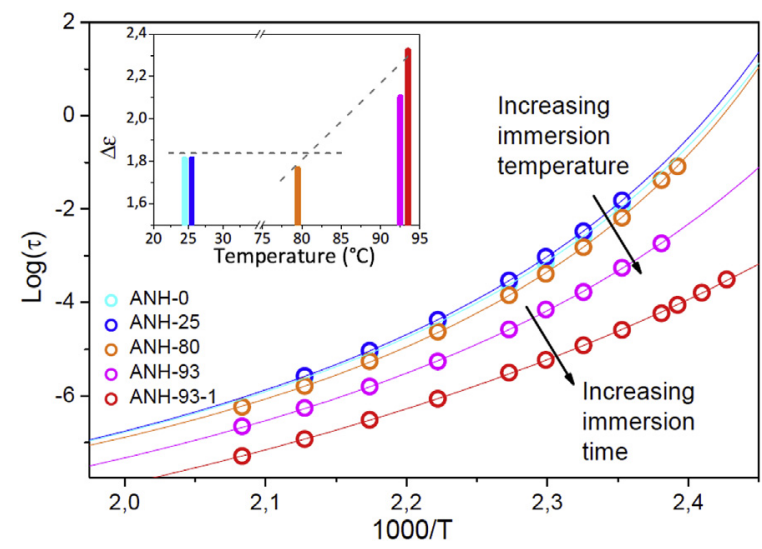

Fig. 5. Relaxation time as a function of reciprocal temperature $(1000 / T)$. Lines stand for the VFT fitting results of the experimental data. INSET Dielectric strength of the segmental process at $167^{\circ} \mathrm{C}$. Lines are just a guide for the eyes. 
Table 3

Glass transition temperature $\left( \pm 0.5^{\circ} \mathrm{C}\right)$ determined by BDS and the $\alpha$ and $\beta$ shape parameters $( \pm 0.02)$ obtained in the fitting procedure for the segmental relaxation at $167^{\circ} \mathrm{C}$.

\begin{tabular}{llll}
\hline Sample & $\operatorname{Tg}\left({ }^{\circ} \mathrm{C}\right)$ & $\alpha$ & $\beta$ \\
\hline ANH-0 & 131.8 & 0.68 & 0.39 \\
ANH-25 & 132.7 & 0.68 & 0.38 \\
ANH-80 & 131.7 & 0.67 & 0.39 \\
ANH-93 & 120.4 & 0.60 & 0.38 \\
ANH-93-1 & 104.2 & 0.55 & 0.38 \\
\hline
\end{tabular}

for ANH-93. In this case, the trend can also be interpreted as a sign of higher mobility, most likely related to an increase of the free volume in the materials, since this allow the chain dipoles to follow the electric field more efficiently (dipoles that otherwise would be completely immobilized or not so strongly oriented).

In order to gain some more insight into these experimental observations and the material heterogeneity resulting from the chemical degradation, the width of the relaxation peak was also analyzed. In this way, Fig. 6 shows the normalized dielectric loss as a function of normalized frequency for all the previously analyzed samples. As shown, the observed widths systematically increase as the immersion temperature (or immersion time at high temperature) increases. A quantitative approach is achieved by employing the following empirical expression [25] for calculating the full width at a half maximum (FWHM):

$F W H M=-0.516+\frac{1.058}{\alpha}+\frac{0.039}{\beta}+\frac{0.563}{\alpha \beta}$

where $\alpha \mathrm{y} \beta$ are the HN shape parameters. As shown in Fig. 6 inset, the maximum $F W H M$ is found for samples degraded at $93^{\circ} \mathrm{C}$. The broadness of the relaxation peak is typically related to the dipole environment. The broader the peak, the more heterogeneous the environment where the relaxation process occurs [17].

Finally, the temperature dependence of the segmental relaxation time was also used to add information about the polymer network structure [26]. The fragility $(m)$ defined as:

$m=\left.\frac{\partial \log (\tau)}{\partial\left(\frac{T_{g}}{T}\right)}\right|_{T_{g}}$

is typically used for characterizing deviations in the temperature

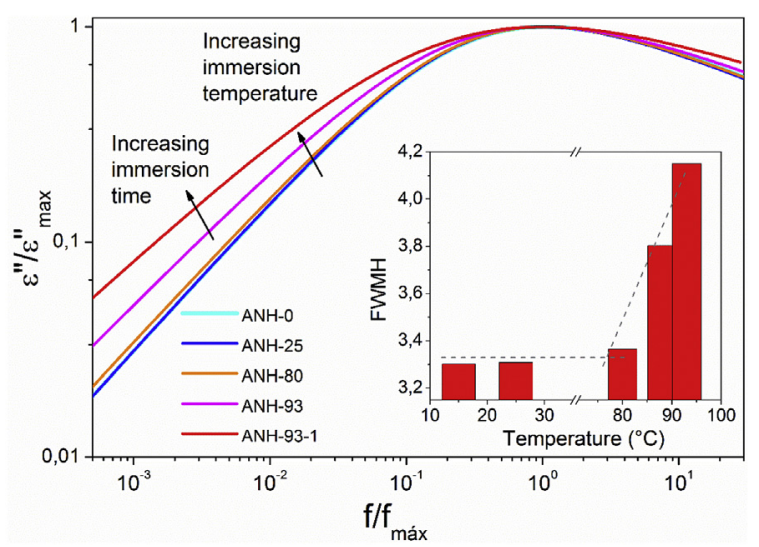

Fig. 6. Normalized dielectric loss as a function of normalized frequency for the segmental relaxation processes of ANH-0, ANH-25, ANH-80, ANH-93 and ANH-93-1. INSET: corresponding FWHM. Lines are just a guide for the eyes.

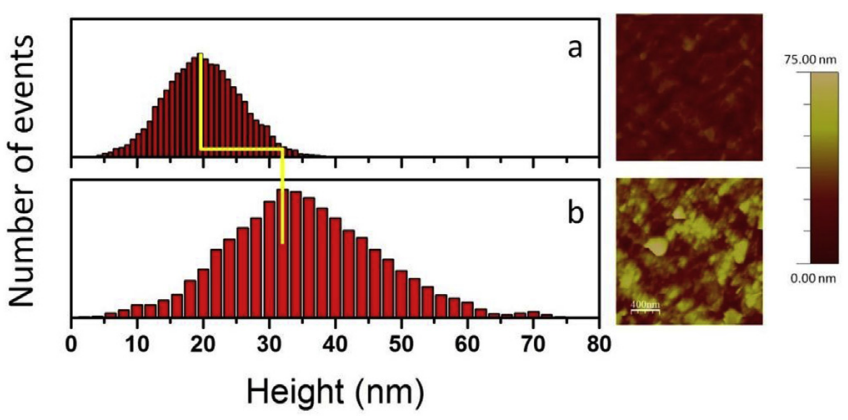

Fig. 7. Topographic profiles for samples degraded in distilled water at $93^{\circ} \mathrm{C}$ during: a) 0 days (ANH-0). b) 60 days (ANH-93-1).

dependence of the relaxation time from an Arrhenius behavior. These polymers with a steep departure from Arrhenius are called "fragiles" while those with an opposite behavior are called "strong". The obtained fragility values for the materials under study are presented in Table 4.

It is worth noticing that fragility of ANH-0 and ANH-25 are very similar, while ANH-80 presents a much higher (123.7) value. ANH93 and ANH-93-1, however, present a large decrease in their observed $\mathrm{m}$ values. These results can be rationalized by taking into account two competing effects. On the one hand, the fragility increases as the chemical reaction takes place and the polymer mobility increases due to the lower crosslink density. On the other hand, the residual concentration of reaction products (plasticizers) also increases, therefore decreasing the polymer fragility [27]. At higher degradation stages the second effect becomes dominant, therefore explaining the observed trend. These results can be also related to the observed changes in secondary dielectric relaxations shown in Fig. SI 3 and to the low frequency conductivity on the imaginary permittivity signal, which increases as the aging time increases (see Fig. SI 5).

\subsection{Degradation process at the nanoscale}

In order to gain some insight on the effects of the degradation process on the networks properties at the nanoscale, the topography and the local DMT modulus (Derjagin-Muller-Toropov modulus [28]) of the materials were studied by means of atomic force microscopy. Fig. 7 presents a comparison between the observed height distribution in ANH-93-1 with respect to ANH-0. As shown, the mean height of the distribution deviates towards larger values (as indicated by the yellow line), while the width of the distributions dramatically increases after 60 days. This observation is in good agreement with the previously proposed material loss after severe degradation, in turn leading to the observed changes in the macroscopic shape and color. Moreover, this result can be also related to the large FWHM increase observed in ANH93-1.

With respect to the evolution of the mechanical properties during the degradation of these materials, Fig. 8 presents

Table 4

Fragility $( \pm 0.5)$ values.

\begin{tabular}{ll}
\hline Sample & $\mathrm{m}$ \\
\hline ANH-0 & 113.5 \\
ANH-25 & 113.6 \\
ANH-80 & 123.7 \\
ANH-93 & 106.4 \\
ANH-93-1 & 95.0 \\
\hline
\end{tabular}



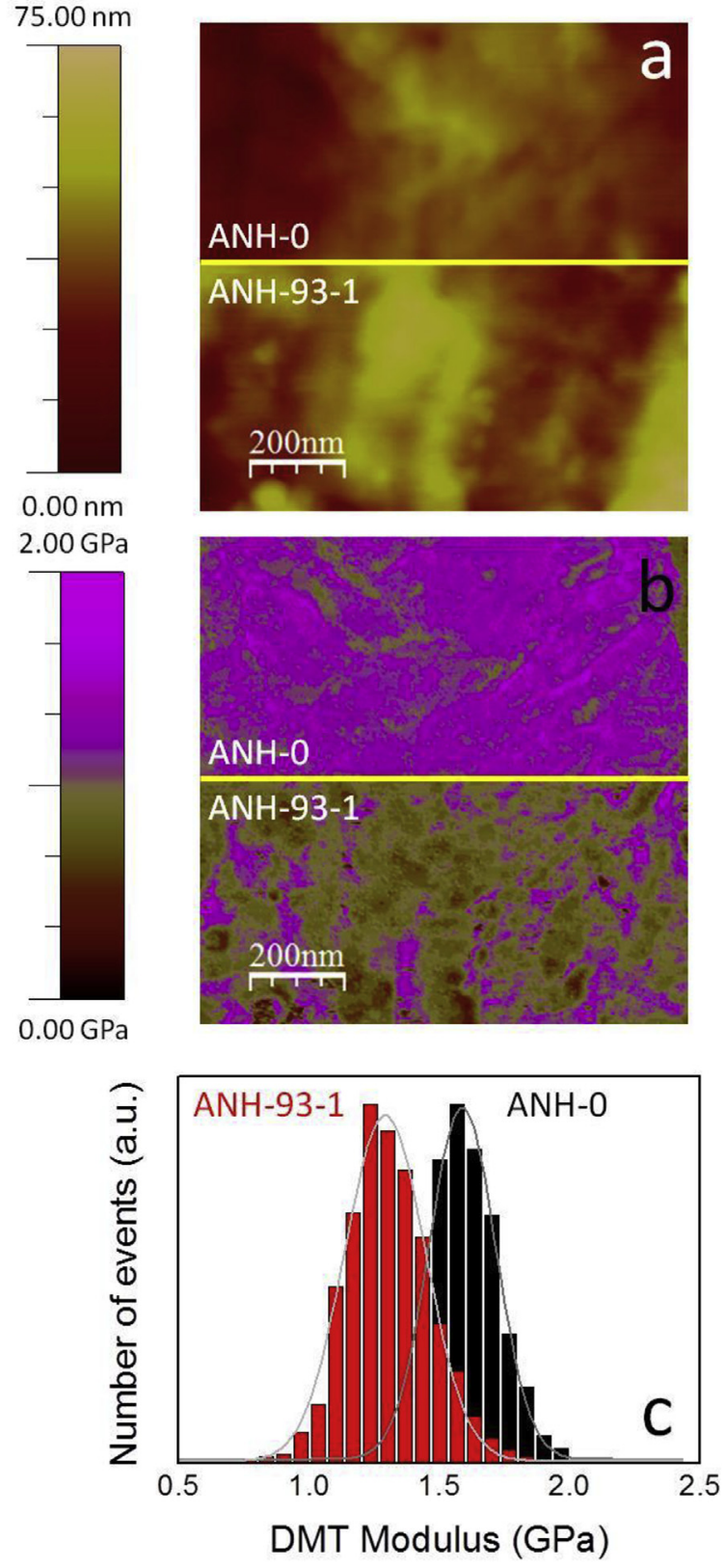

Fig. 8. a) ANH-0/ANH-93-1 topography. b) DMT Modulus image of ANH-0/ANH-93-1. c) DMT Modulus histogram. Both histograms were fitted by using Gaussian functions: FWHM values for ANH-93-1 and ANH-0 were 0.365 and $0.301 \mathrm{GPa}$, respectively.

comparative images of topography and DMT modulus for ANH0 and ANH-93-1 samples. Since the measurements were performed at room temperature, well below the glass transition temperature but still above the temperatures at which the $\beta$ relaxation-related movements are frozen (see the relaxation map in Fig. SI 4). The DMT modulus could be affected by the changes in the $\beta$ relaxation rather than the changes in the $\alpha$-relaxation (which, as stated before, is "frozen" at the AFM experimental conditions). The connection between the $\beta$ relaxation and the mechanical properties of the polymer has been extensively studied. Bershtein [29] has reported that the $\beta$ relaxation can be considered as the "activation barrier" for solid-phase reactions like deformation. Therefore, the strength of the $\beta$ relaxation can be related to how strongly a polymer responds to these solid-phase reactions. For example, Nelson has reported that the $\beta$ relaxation can be related to vibration damping, an effect which is also true for acoustical damping [30]. In both cases, the strength of the $\beta$ relaxation is taken as a measurement of how effectively a polymer will absorb vibrations. However, Boyer [31] and Heijboer [32-35] showed that this information needs to be considered with care, as not all the $\beta$ relaxations correlate with toughness or other properties. This can be due to misidentification of the relaxation, or that the relaxation does not sufficiently disperse energy. A working rule of thumb [36] is that the $\beta$ relaxation must be related to either localized movement in the main chain or very large side chain movement to sufficiently absorb enough energy. The relationship of large side chain movement and toughness has been extensively studied in polycarbonate by Yee [37] as well as in many other tough glassy polymers [38].

ANH-93-1 DMT modulus presents a decrease of about 30\% with respect to the neat sample (ANH-0). Moreover, there is also a clear change in the local heterogeneities of ANH-93-1 modulus, as reflected by the broader DMT modulus distribution in Fig. 8c (the FWHM is 20\% larger for ANH-93-1).

\subsection{Rationalization of results}

In summary, the analysis of the networks dynamics, water uptake and calorimetric behavior, suggest a strong chemical degradation process affecting the materials, i.e.: as the number of destroyed covalent bonds increases with immersion time, the configurational restrictions to the molecular motions grow weaker, thus causing an increase in the configurational entropy or free volume $[39,40]$. This increase in the network free volume (and also in number of chain ends) causes the observed fastening and strengthening (see Fig. 5) of the dielectric response. The increasing FWHM shows that the destruction of the polymer network bonds also increases the dispersion of segmental relaxation times (the calculated $m$ values also evidence this effect). In addition, these results also find correlation in the observed nanomechanical behavior, where the most degraded materials present the lower DMT modulus, as well as broader distributions.

\section{Conclusions}

Water absorption and degradation processes in epoxy networks were characterized by a combination of different experimental techniques. Differential scanning calorimetry, broadband dielectric spectroscopy and atomic force microscopy were employed to gain insight into the physical-chemistry of epoxy-anhydride networks. It was observed that the progressive destruction of covalent bonds caused by the degradation processes increases the configurational entropy of the materials, directly affecting their segmental relaxation, their thermal and mechanical properties and, ultimately, their in-service performance.

\section{Acknowledgements}

The authors gratefully acknowledge the valuable scientific discussions with Dr. Silvina Cerveny.

This work was partially Supported by the Spanish Ministry "Ministerio de Economía y Competitividad", code: MAT201563704-P (MINECO/FEDER, UE) and by the Argentine government funded scholarship program, BEC.AR.

\section{Appendix A. Supplementary data}

Supplementary data related to this article can be found at http:// dx.doi.org/10.1016/j.polymdegradstab.2017.06.010. 


\section{References}

[1] K.A. Barrera-Rivera, L. Peponi, Á. Marcos-Fernández, J.M. Kenny, A. MartínezRicha, Synthesis, characterization and hydrolytic degradation of polyesterurethanes obtained by lipase biocatalysis, Polym. Degrad. Stab. 108 (2014) $188-194$

[2] F. Belan, V. Bellenger, B. Mortaigne, J. Verdu, Relationship between the structure and hydrolysis rate of unsaturated polyester prepolymers, Polym. Degrad. Stab. 56 (3) (1997) 301-309.

[3] B. Jacques, M. Werth, I. Merdas, F. Thominette, J. Verdu, Hydrolytic ageing of polyamide 11. 1. Hydrolysis kinetics in water, Polymer 43 (24) (2002) 6439-6447.

[4] L.E.O.J. Kasehagen, I. Haury, C.W. Macosko, D.A. Shimp, Hydrolysis and blistering of cyanate ester networks, J. Appl. Polym. Sci. 64 (1) (1996) 107-113.

[5] E. Richaud, P. Gilormini, M. Coquillat, J. Verdu, Crosslink density changes during the hydrolysis of tridimensional polyesters, Macromol. Theory Simul. 23 (5) (2014) 320-330.

[6] J. Crank (Ed.), The Mathematics of Diffusion, Oxford University Press, 1979.

[7] R. Leger, a. Roy, J.C. Grandidier, Non-classical water diffusion in an industrial adhesive, Int. J. Adhes. Adhes. 30 (8) (2010) 744-753.

[8] M.K. Antoon, J.L. Koenig, Irreversible effects of moisture on the epoxy matrix in glass-reinforced composites, Composites 12 (4) (1981) 298.

[9] G.Z. Xiao, G.Z. Xiao, M. Delamar, M. Delamar, M.E.R. Shanahan, M.E.R. Shanahan, Irreversible interactions between water and DGEBA/DDA epoxy resin during hygrothermal aging, J. Appl. Polym. Sci. 65 (3) (1997) 449-458.

[10] V. Bellenger, M. Ganem, B. Mortaigne, J. Verdu, Lifetime prediction in the hydrolytic ageing of polyesters, Polym. Degrad. Stab. 49 (1) (1995) 91-97.

[11] P. Davies, Y.D. Rajapakse (Eds.), Durability of Advanced Composites in a Marine Environment, Springer, 2014.

[12] L. Gautier, B. Mortaigne, V. Bellenger, J. Verdu, Osmotic cracking nucleation in hydrothermal-aged polyester matrix, Polymer 41 (7) (2000) 2481-2490.

[13] P. Luukkonen, T. Maloney, J. Rantanen, H. Paulapuro, J. Yliruusi, Interaction a novel approach using thermoporosimetry, Pharm. Res. 18 (11) (2001) $1562-1569$.

[14] S. Jähnert, F. Vaca Chávez, G.E. Schaumann, a Schreiber, M. Schönhoff, G.H. Findenegg, Melting and freezing of water in cylindrical silica nanopores, Phys. Chem. Chem. Phys. 10 (39) (2008) 6039-6051.

[15] J.P. Pascault, H. Sautereau, J. Verdu, R.J.J. Williams, Thermosetting Polymers, Marcel Dekker, 2002.

[16] J. El Yagoubi, G. Lubineau, F. Roger, J. Verdu, A fully coupled diffusion-reaction scheme for moisture sorption-desorption in an anhydride-cured epoxy resin, Polym. (United Kingdom) 53 (24) (2012) 5582-5595.

[17] F. Kremer, A. Schönhals, Broadband Dielectric Spectroscopy, Springer, 2003.

[18] M.M. Kummali, L.A. Miccio, G.A. Schwartz, A. Alegría, J. Colmenero, J. Otegui, et al., Local mechanical and dielectric behavior of the interacting polymer laye in silica nano-particles fi lled SBR by means of AFM-based methods, Polymer 54 (18) (2013) 4980-4986.

[19] M. Monasterio, J.J. Gaitero, E. Erkizia, A.M. Guerrero, L.A. Miccio, J.S. Dolado, et al., Effect of addition of silica- and amine functionalized silica- nanoparticles on the microstructure of C-S-H gel, J. Colloid Interface Sci. 450 (2015) 109-118.
[20] M.M. Kummali, L.A. Miccio, J. Colmenero, Study of the dynamic heterogeneity in poly(ethylene- ran -vinyl acetate) copolymer by using broadband dielectric spectroscopy and electrostatic force microscopy, Macromolecules 46 (18) (2013) 7502-7512.

[21] L.A. Miccio, J. Otegui, M.E. Penoff, P.E. Montemartini, G.A. Schwartz, Fluorinated networks dynamics studied by means of broadband dielectric spectroscopy, J. Appl. Polym. Sci. 132 (42) (2015) 1-9.

[22] L.A. Miccio, M.M. Kummali, P.E. Montemartini, P.A. Oyanguren, G.A. Schwartz, Á. Alegría, Determining concentration depth profiles in fluorinated networks by means of electric force microscopy, J. Appl. Polym. Sci. 135 (6) (2011) 1-6.

[23] S. Havriliak, S. Negami, A complex plane representation of dielectric and mechanical relaxation processes in some polymers, Polymer 8 (1967) $161-210$.

[24] (a) H. Vogel, Phys Z 22 (1921), 64 5;

(b) G.S. Fulcher, J. Am. Ceram. Soc. 8 (1923) 339;

(c) G. Tammann, W.Z. Hesse, Anorg. Allg. Chem. 156 (1926) 245.

[25] G.A. Schwartz, J. Colmenero, Á. Alegría, Single component dynamics in miscible poly(vinyl methyl ether)/polystyrene blends under hydrostatic pressure, Macromolecules 40 (9) (2007) 3246-3255.

[26] K. Kunal, C.G. Robertson, S. Pawlus, S.F. Hahn, A.P. Sokolov, Role of chemical structure in fragility of polymers: a qualitative picture, Macromolecules 41 (19) (2008) 7232-7238.

[27] G.A. Schwartz, M. Paluch, N. Alegría, J. Colmenero, High pressure dynamics of polymer/plasticizer mixtures, J. Chem. Phys. 131 (4) (2009) 044906.

[28] B.V. Derjaguin, V.M. Muller, Y.P. Toporov, Effect of contact deformations on the adhesion of particles, J. Colloid Interface Sci. 53 (2) (1975) 314-326.

[29] V. Bershtein, V. Egorov, Differential Scanning Calorimetry in the Physical Chemistry of Polymers, Ellis Horwood, Chichester, 1993.

[30] F.C. Nelson, Shock and vibration digest 26 (2) (1994) 11.

[31] R.F. Boyer, Dependence of mechanical properties on molecular motion in polymers, Polym. Eng. Sci. 8 (3) (1968) 161-185.

[32] J. Heijboer, Secondary loss peaks in glassy amorphous polymers, Int. J. Polym. Mater $6(1-2)(1977) 11-37$.

[33] J. Heijboer, Dynamic mechanical properties and impact strength, J. Polym. Sci. Polym. Symp. 16 (7) (1968) 3755-3763.

[34] R.J. Morgan, L.E. Nielsen, The dynamic mechanical properties of polymers at cryogenic temperatures, J. Macromol. Sci. Phys. 9 (2) (1974) 239-253.

[35] J. Bussink, J. Heijboer, J.A. Pins (Eds.), In Physics of Non-crystalline Solids, 1965, p. 388. Amsterdam.

[36] G. Johari, Secondary relaxations and the properties of glasses and liquids, Lect. Notes Phys. 277 (1987) 90-112.

[37] A.F. Yee, S.A. Smith, Molecular structure effects on the dynamic mechanical spectra of polycarbonates, Macromolecules 14 (1981) 54-64.

[38] G.A. Gordon, Glass transition in nylons, J. Polym. Sci. A2 9 (9) (1971), 1963-1702.

[39] M. Beiner, K.L. Ngai, Interrelation between primary and secondary relaxations in polymerizing systems based on epoxy resins, Macromolecules 38 (16) (2005) 7033-7042.

[40] B. Fitz, Reorientational dynamics and intermolecular cooperativity of reactive polymers. 1. Model epoxy - amine systems, Macromolecules 30 (18) (1997) 5227-5238. 